\title{
Structural Conservation Engineering in Practice: Lessons Learned
}

\author{
A. Drougkas \& E. Verstrynge \\ Building Materials and Building Technology Section, KU Leuven
}

\begin{abstract}
Conservation engineering, as stated by the components of the term, draws from both conservation principles and modern engineering practice in an attempt to balance the demands of both preservation values and comprehensive structural design. As such, the realities of the building industry and the principles of conservation practice, when not being hard to reconcile or outright contradictory, leave the structural engineer with very little room for envisaging and realizing creative and effective intervention proposals. Furthermore, structural engineers are often sidelined in the decision making process of intervention design, in essence playing but a small role in the strategic planning of architectural conservation projects. The additional constraints imposed by financial, temporal and administrative limitations generally leave but a narrow spectrum of workable and realistic choices to structural engineers involved in architectural heritage.

In this paper, several salient characteristics of the role of structural engineers employed in architectural heritage projects are outlined. These characteristics, assembled from practical experience in both the professional and academic spheres, as well as from their interaction, are contrasted against ideal practice in an effort to highlight obstacles yet to be overcome. Illustrating examples are drawn from relevant case studies, both from past as well as from more recent projects.

A number of possible workarounds to the challenges faced by structural conservation engineers are finally outlined. The advances in engineering technology, materials engineering and building life-cycle and construction management techniques open new possibilities for interdisciplinary collaboration between all the design groups and stakeholders engaged in structural conservation projects.
\end{abstract}

\section{INTRODUCTION}

Modern conservation engineering is the ever evolving product of the advances in several fields related to, among others, architecture, archaeology and structural engineering. It has gone through numerous changes in regards to its theoretical background and its practical application, maintaining fragments of its previous incarnations along the way. Ideally, each individual contributing aspect of conservation engineering evolves taking into account new breakthroughs in its own field while taking into account the suggestions of its mutually supporting partners from other disciplines.

The content of the paper is motivated by the experience of the authors in conservation engineering projects, research endeavors and their relation to such projects, the education of structural conservation engineers and their integration in multidisciplinary conservation teams. It draws upon experience mainly gathered in Greece, Spain and Belgium and is informed by conservation practice from other settings as published or otherwise made available. These experiences are weighed against ideal theory and prac- tice, concluding with remarks for possible improvement and expansion where it is deemed necessary.

\section{THE CONTEXT}

\subsection{Nature of Projects}

Conservation projects involving historic structures may be categorized according to two parameters, one qualitative and one partially quantitative. The former involves the type of ownership of the object: whether it be privately owned or owned and managed by a public institution, such as the state, organized religious institutions etc. The latter parameter involves the importance of the structure, stemming from its size, location, nature of intended use etc. This, in turn, is translated into the degree of public visibility afforded to it and, as a general consequence, the budget available for its restoration and public projection. This categorization is carried out independently of the evaluation of the object in terms of its age, historical importance and cultural value.

Major historic building projects are rather limited in number, thus not providing ample opportunity for 


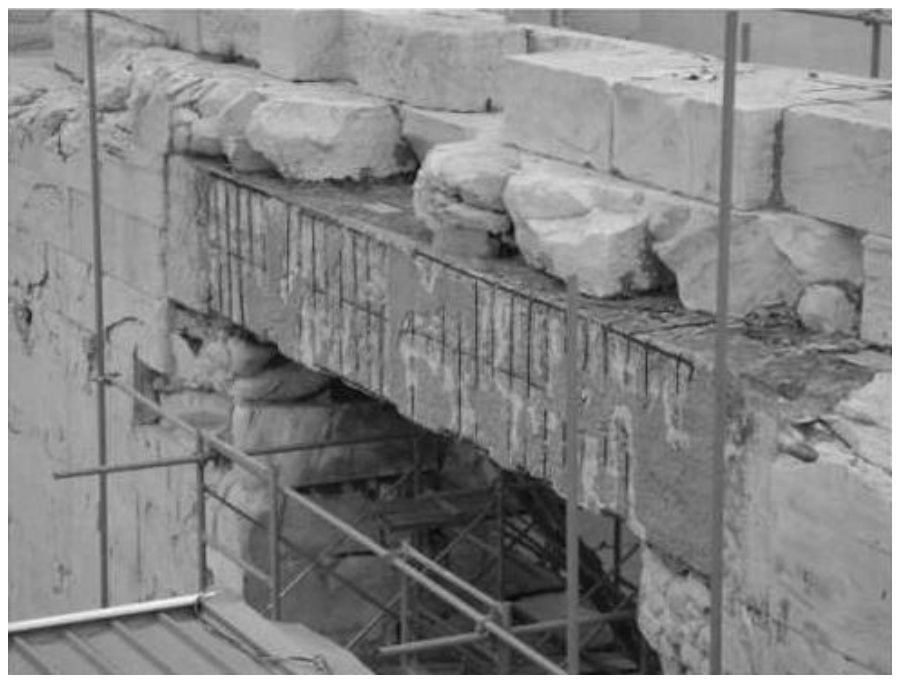

Figure 1: Reinforced concrete beam used in the restoration of the Parthenon, Athens (photo by A. Drougkas).

practical training to conservation specialists of any involved discipline. Further, due to the increased prestige of such projects, their financial importance and the potential for their exploitation for political purposes, progress in such projects may be either disproportionally accelerated or, contrarily, stagnated due to external interference and pressure. The restoration of the monuments of the Acropolis in Athens constitute such as example: reinforced concrete was adopted in order to, among other reasons, hasten the completion of the project in time for the centennial of the modern Greek state in 1932 . The acceptance at that time, as stipulated in the Athens Charter, of reinforced concrete in restoration was only incidental (The Athens Charter 1931) and was not the main motivating factor (see Figure 1).

Major projects of all distinctions may, therefore, not be ideal training ground for structural engineers engaged in conservation projects due to their scarcity and exposure to being molded by external parameters. This fact leaves small projects, for the most part privately owned, as the main field of practice in the area of assessment and intervention design on existing structures.

\subsection{Profile of Private Owners and Projects}

The vast majority of restoration projects involve small buildings of low visibility owned by private individuals. In many national-level contexts, restoration of an existing building for the same type and magnitude of use is often cost-effective compared to demolition and replacement. This is the main reason for the preponderance of these projects and their appeal to owners of limited or modest financial means. It is very often the case that private owners are unaware of, or indifferent to, conservation principles, however their property might be endowed in terms of features of cultural and historic value. Further, their grasp of the demands of modern structural design is necessarily vague, given the radical updating of structural design philosophy and means in recent decades.

As is expected, the time devoted to planning of the project, assembling the necessary historic data, carrying out the required geometric survey and material tests and preparing the final design proposal is often curtailed. This constitutes a severe obstacle in setting specialized skills in motion. Additionally, and especially in the case of buildings planned for private residential use, the budget for structural interventions directly competes with the budget allocated for the refit of the building over a limited pool of resources.

The lack of initial planning may potentially introduce obstacles in later stages of the project. Owners frequently extend demands for heavier than initially anticipated use, additions to the structure or removal of main structural elements to accommodate changes in the architectural plan. In addition to the potential increase in the cost of effecting the necessary interventions, these alterations entail the risk of loss of cultural value of the building if no workaround to avoid heavy interventions can be devised. On the flip-side, a greater emphasis on overall structural safety is prioritized, effectively satisfying at least one of the design goals of the structural engineer.

The involvement of structural conservation engineers in small scale projects is an important formative experience due to its being rather common in occurrence and demanding in its imposed restrictions. It is more probable that collective experience gained in this regard should feed into the technical know-how applied in major projects.

\subsection{Conservation Principles}

Structural engineers active in conservation projects should be sufficiently familiar with conservation principles in order to effectively function in multidisciplinary teams. It is often the case that structural engineers long employed in such projects have become accustomed to the demands of conservation principles. However, these principles are often in direct conflict with the demands of modern structural design philosophy. Conservation principles, particularly in the case where seismic design is a priority, are nearly impossible to abide to without severe compromises in structural design and vice versa.

Disregarding structural design demands may potentially lead, in the case of a seismic event, to significant structural damage, potentially leading to loss of character and cultural value higher than that affected by an overly heavy, if necessary, strengthening intervention. Additionally, the increase in the risk of injury or loss of life may not be justifiable for the sake of adhering to conservation principles in the case of monuments highly accessible to the public at all times. 


\section{INTERDISCIPLINARITY}

\subsection{Role in Conservation Teams}

It is a very frequent phenomenon that structural engineers find themselves at a disadvantage in multidisciplinary conservation teams. They role is often seen as purely ancillary or outright interfering with the pursuance of conservation principles. They are often faced with a reluctance to be accepted as experts in conservation at all, but are rather admitted as generalists going through the motions related to their discipline. Experience in the field may be seen in a favorable light, but academic training and research accomplishments are not as positively embraced.

Despite invariably being unable, and in any case not expected, to be familiar with all aspects of structural engineering, conservation architects often infringe on the consulting work of structural engineers at a fundamental level. The misconceptions concerning hazards associated with a given structural typology, the structural contribution of specific elements and the effectiveness, or lack thereof, of various interventions may lead to the implementation of ineffective intervention plans, the allocation of insufficient, or excessive, funds to structural works and delays in implementation.

As an example, the debate on the function and pathology of metallic ties in ancient monuments is here mentioned (see Figure 2). In the restoration works of the Parthenon, significant funds and effort have been expended in the replacement of the iron connecting elements in the walls of the monument. However, there does not appear to be a clear consensus on the actual contribution to structural stability afforded by these elements, nor on the exact interpretation of the pathology associated with their failure (Psycharis et al. 2010, Toumbakari 2008). Research in this area is ongoing.

\subsection{Cooperation with Fellow Engineers}

In a national or regional context, the pool of available, experienced and skilled structural engineers with a certain degree of acquaintance with conservation principles is small. At its core it is composed of individuals and SMEs with established methods and techniques, as well as an established clientele. The resulting exchange of knowledge between practitioners is often limited, unless motivated by cooperation in a project or in a specialized consulting capacity.

The relationship of structural engineers with other consulting disciplines employed in the same project is often inefficient. The results and designs of each consulting component are generally passed on through the pipeline, with limited or flawed exchange of data, analysis results and final designs. Time constraints and lack of shared databases, combined with rigid methodology and planning do not allow for flexible cooperation between structural engineers, mechanical, electrical and plumbing engineers, surveyors and geotechnicians, to name a few.

\section{KNOWLEDGE DRIVEN DESIGN}

\subsection{Research Findings}

The preceding few decades have seen a significant increase in the amount, width and depth of research endeavors concerning diverse facets of the analysis of historic structures: construction material design, advanced analysis methods for elements, buildings and conglomerates, risk assessment, seismic design and damage prediction and categorization to name a few. This has produced a wealth of available knowledge and numerous experienced and highly active research groups. However, funding for further research related to conservation engineering and heritage structures, unless framed in a sustainability context appears to be becoming a secondary priority for international funding bodies. For example, the H2020 work Programme for the years 2018-2020 includes Focus Areas designed around four political priorities: (a) a low-carbon, climate resilient future; (b) circular economy; (c) digitising and transforming European industry and services; and (d) security union. Only the first is marginally related to heritage. In a sustainability context, conservation engineering generally has a grey energy advantage over new construction due to its limited reliance on the production of excessive amounts of new construction materials. This counteracts its potential lower energy performance during operation, which would place it at a disadvantage compared to the new construction promoted by the green building agenda.

Concerning the absorption of the produced knowledge on the subject, it is faced by a limiting factor. The building sector is inherently conservative and slow to adopt. New methods and materials are introduced at a very slow pace or not at all, partly owing to established practice in the sector and lack of effective dissemination outside of the academic sphere. This can be prohibitive for the adoption both of cutting edge as well as of traditional materials and techniques proven to be effective in structural design. Simultaneously, however, slow adoption is not without its benefits. Durability and general compatibility concerns can be detected and addressed when new methods are applied on a small scale before introduction to large scale cases.

Finally, research findings are often reliant on structural analysis methods, construction techniques and material technology that may introduce increased costs in realization. Such analysis methods include collapse load limit analysis, discrete element modeling and nonlinear finite element analysis. Conversely, advanced materials are drawn from the fields of selfsensing and self-healing technology or the area of 


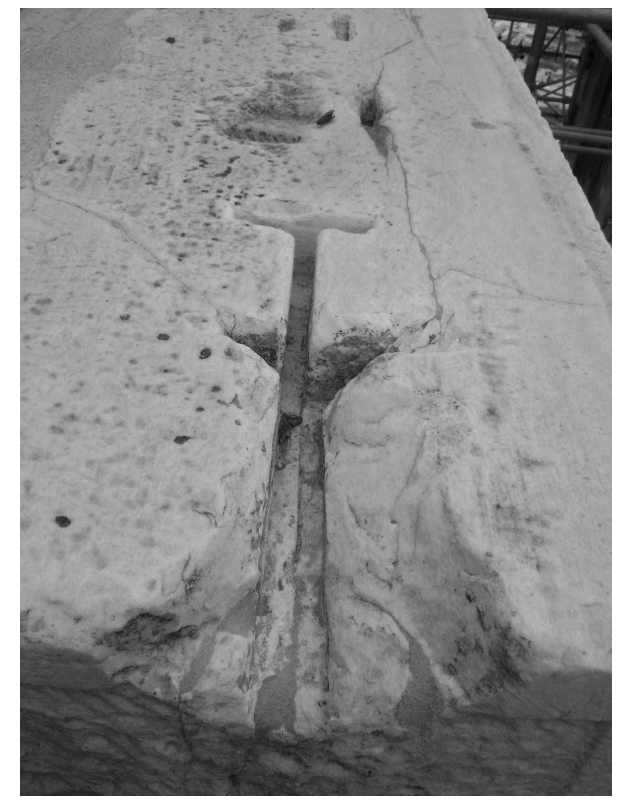

(a)

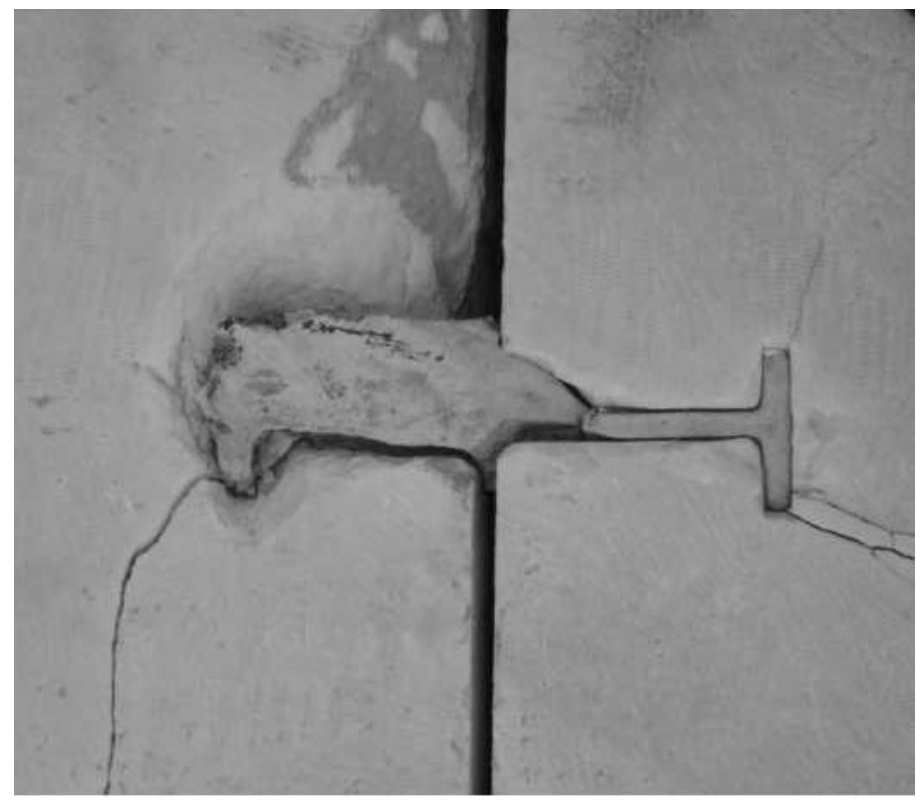

(b)

Figure 2: Damage to marble elements of the Athens Parthenon due to the presence of connecting elements: (a) loading-induced and (b) corrosion-induced damage (photos by A. Drougkas).

nano- and micro-materials. These findings, however, are the most effective way of promoting expertise and specialization in the field of conservation engineering, while simultaneously providing sound solutions, and ought, therefore, to be promoted as much as feasible.

\subsection{Teaching and Acquisition of Experience}

Currently, and traditionally, there is a near complete absence of undergraduate courses in engineering focusing on conservation. Most, if not all, academic education options available in engineering courses are confined to post-graduate courses, few of which are strictly engineering focused, rather than architecture oriented. The concept of interdisciplinarity is often instilled in the students following the curriculum, but is not concretely explained in practical terms, unless tackled in the shape of integrated projects focused on specific case studies.

Post education and professional fora do exist, fostering the exchange of knowledge and experience in conservation engineering, such as ISCARSAH (iscarsah.org) and WTA (wta-international.org). Such organizations, however, are often of an international character, therefore having a wide focus and often being difficult to convene on a regular basis and with an agenda dedicated to tackling specific urgent problems. Hence the importance of regional groups, e.g. WTA-Nederland-Vlaanderen (wta-nlvl.org), Historic England (historicengland.org.uk) and Historic Environment Scotland (historicenvironment.scot).

Finally, a potential source of information and knowledge are public dissemination events motivated by the beginning, progress or conclusion of major architectural conservation projects. Such events may be sponsored both by major private owners and by public authorities. These dissemination efforts rarely focus on the structural engineering aspects of the project, therefore missing a significant potential for stimulating the exchange of knowledge and debate on technical matters related to conservation engineering.

\section{IN PRACTICE}

\subsection{Design Codes}

Modern structural engineering practice, both concerning new and existing buildings, is largely defined by the demands and limitations imposed by codes and standards. As stated above, the building sector is heavily regulated by analysis, design and execution standards for the sake of establishing a minimum safety and performance level, harmonizing structural assessment methods and facilitating construction practice, all in the form of a legally binding framework.

Historic buildings arguably fall in the general domain of existing structures, and are therefore, at least in principle and for the sake of argument, approachable through the lens of generic design standards. Design standards can be a powerful tool in the hands of the structural engineer for the purpose of objectively laying down the demands and limitations of every proposed intervention scheme. Quantification is a line of defense and a means of supporting one's opinions in that regard. This quantification is made on the requirement for satisfying the safety equation, here presented simplistically as

$$
E_{d} \leq R_{d}
$$

where $E_{d}$ is the design action (deformation, force, stress, etc.) and $R_{d}$ is the design resistance (allowable 
deformation, force capacity, allowable stress etc). The strength of such arguments, however, is only proportional to the completeness and accuracy of the assessment techniques employed in the project, which in the case of historic structures are often lowered due to limitations in destructively interfering with the fabric of the building. On the other hand, the imposed demands are quite often capable of being defined with a very high degree of accuracy, regardless of the completeness of the geometric survey, the determination of the material properties or the study of the structural detailing.

The demands imposed by analysis and design standards have dramatically increased in the preceding two decades, owed to a shift in overall design philosophy, re-evaluation of seismic risk maps and the development of more precise and comprehensive analysis methods. Full conformity with these demands, especially in the case of seismic design, will almost without fail lead to heavy interventions in historic buildings, whether they have already suffered damage or not. This is true despite the appropriately adjusted statistical approaches for the calculation of capacity and demand adopted for existing structures compared to new construction (CEN 2005). There are, however, in effect national codes focusing on the analysis of historic structures (Ministero per i Beni e le Attività Culturali 2008). Such codes promote the use of advanced assessment techniques and sophisticated analysis methods, while at the same time establishing different performance levels conducive to the acceptance of lighter interventions.

\subsection{Traditional Building Practice}

Traditional building and intervention methods and materials play an important part in conservation engineering. Their preference over new techniques is advocated by the Venice Charter (The Venice Charter 1964). Due to their advantage in proven compatibility, low technological and execution complexity and often enhanced durability, they are preferred even when they cannot be fully verified theoretically or through detailed calculation.

While significant experience has been accumulated in the application of such methods as the addition of metallic ties and the confinement of pillars, excessive reliability in traditional methods leads to stagnation in the adoption and improvement of technologically advanced approaches. This effect is coupled with the virtually complete pre-determination of the available intervention options by the building typology and insitu material to impose a restriction on implementing creative solutions. The weight of evidence generally falls on proving the traditional methods inadequate rather than proving innovative solutions effective, which is in conflict with the conceptual basis of knowledge based design.

Highlighting examples may be drawn from the field of interventions on historic masonry structures. The application of metallic tie rods and metallic confining strips applied to horizontal spans and vertical pillars respectively are methods that have seen extensive use over centuries. While metallic ties are susceptible to corrosion, thus posing a threat to the masonry elements to which they are anchored, the proposal of mechanically anchored FRP rods and strips for the same purpose or as a temporary measure (Verstrynge et al. 2010) may be met with skepticism by conservators, despite the material's inertness and regardless of its cost related or technological advantages or disadvantages compared to plain or stainless steel (see Figure 3). On the other hand, the effect of injecting lime based grout in three-leaf masonry is invariably seen as beneficial and accepted even in the absence of the relative calculations quantifying its contribution to stiffness and resistance.

\subsection{Building Authorities}

In the general case, listed buildings are managed by specially constituted building authorities, supervising and ruling on the acceptability of most alterations and interventions upon them. The extent of their prerogative is defined by law and is usually comprehensive, as is their obligation to thoroughly check all aspects of planned interventions.

In practice, many such authorities are understaffed, particularly as concerns structural engineers. This may lead to lack of oversight or the forwarding of demands for alterations at later stages in the project, including after the actual commencement of construction.

\subsection{Building Contractors}

Similarly to the case of structural engineers, competent and experienced building contractors specializing in works for architectural heritage buildings form a rather small pool in the regional or national context. They constitute an indispensable part of the decision making process in light of the fact that all proposed interventions are ultimately reliant on the capacity of the building contractor to execute them efficiently and cost-effectively.

Due to geographical mobility restrictions and established construction practices, building contractors are often limited in their adaptability and adoption of new methods and materials. As highlighted above, this goes hand in hand with the preponderance of traditional intervention techniques in historic buildings.

\section{POTENTIAL REMEDIES}

\subsection{Practical Tools}

Interdisciplinarity in its practical aspect ought to be based on data exchange. Research is ongoing to de- 


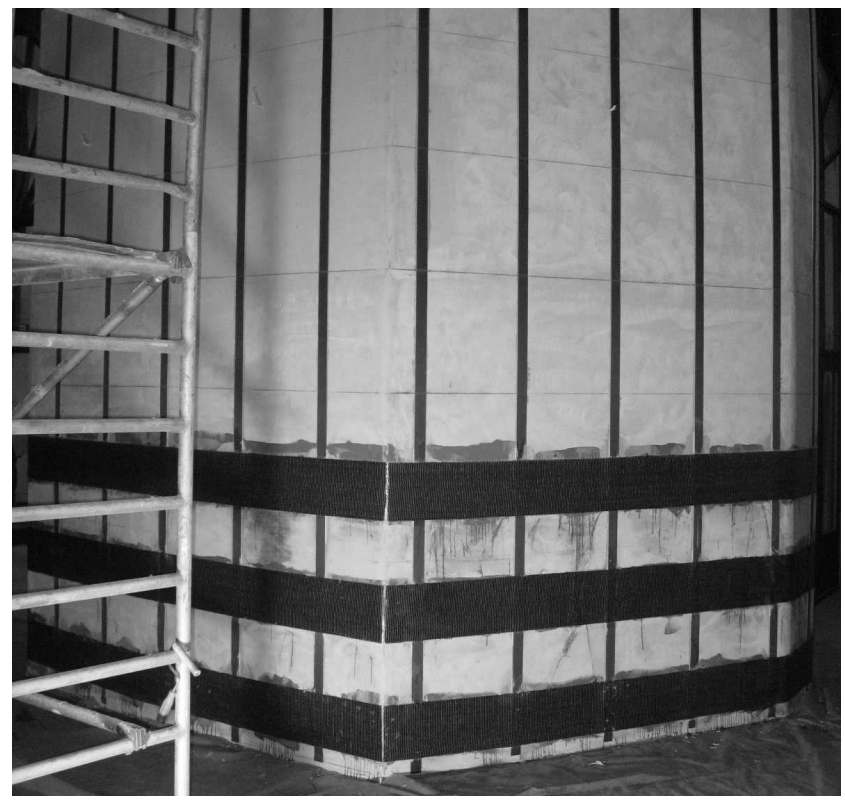

(a)

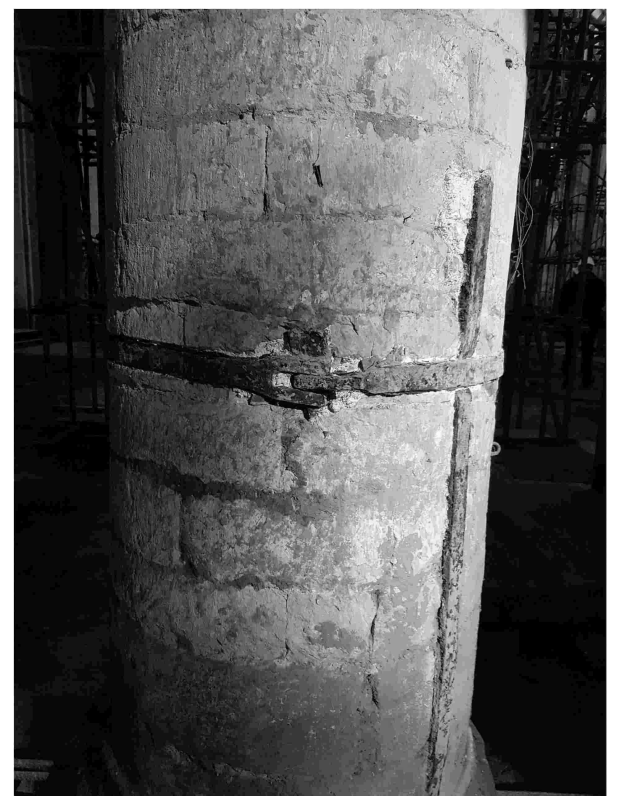

(b)

Figure 3: Confinement of masonry pillar elements: (a) FRP confinement (photo by Triconsult) and (b) iron confinement (photo by A. Drougkas).

velop platforms accommodating efficient data exchange from different sources, such as geometric survey, heritage and historic data, architectural planning and structural analysis. These may be developed in the context of Building Information Modeling on a single building scale (Bassier et al. 2018). Similarly, Geographic Information System can function on the same principle in an enlarged scale, encompassing entire historic settlements or urban centers (Heras Barros 2014).

The necessity for designing against emerging types of risk raises further the need of input from engineering specialists (United Nations Office for Disaster Risk Reduction 2015). Extreme environmental action, such as ground subsidence and uplift, induced earthquake, wind, flooding and human aggression require the input of specialized civil and structural engineers for the development of risk mitigation and protection schemes for historic buildings. Additionally, robust and reliable solutions for previously hard to solve problems in structural engineering, such as rocking of stone blocks under earthquake loading, are being continuously proposed. More importantly, these methods are being coupled with specified performance criteria directly applicable in structural design (Lagomarsino 2015).

The confluence of new tools and increased requirements is an ideal opportunity for reestablishing the shape of cooperation of all consulting disciplines in conservation projects on a new basis.

\subsection{Theoretical Arsenal}

As already stated, the design philosophy and methodology basis established by design codes serves as a convenient starting point for the structural analysis of historic structures. The general concepts pervad- ing these codes as far as existing structures are concerned ought to be attractive to conservators, as they are founded on the principle of preventive conservation: the design is carried out against a foreseeable action rather than being purely restorative.

The quantitative basis of design codes can be in principle adapted to heritage structures with a number of operational modifications. These rely on three key parameters: (a) the desired performance level, (b) the desired life span of the building and (c) the level of accessibility of the structure (Spyrakos 2015). The demand against a given design load, such as earthquake, may be statistically determined as a function of these three parameters. Assuming sufficient knowledge of the material properties and dominant failure mechanisms, a parametric study around these three axes allows to thus fully determine the adequacy of a given repair or strengthening scheme for a given limit state, the time period for which the scheme will be effective before requiring redesign and the amount of visiting hours per day that may be allowed for the scheme.

Special care needs to be exercised in the adoption of code inspired approaches for performance based design of historic, and indeed of all, structures. Inexperienced engineers may be tempted to implement the requirements of design codes without fully grasping the behavior of large structural systems, an approach which can lead to egregious errors in seismic design and the implementation of ineffective solutions. Therefore, a balance needs to be struck between (a) allowing well-informed engineering judgment in analysis and design and (b) accommodating the influx of new professionals, in dire need of guidance, to preservation engineering through proper training and an informative code framework. 


\subsection{Knowledge in Use}

Assisted in their efforts by the above mentioned practical and theoretical tools, structural engineers can make decisive contributions in any interdisciplinary context. The professional experience and research findings accumulated up to this point can be brought to bear only through the involvement of structural engineers at every stage of the project.

Acquaintance with knowledge based tools can assist in informed decision about the critical aspects of several methods employed in the intervention design process. Experience in building pathology can direct geometrical and damage survey efforts for the identification of critical failure modes and their indicators. The diagnosis of current and the prediction of future damage through the use of advanced techniques relies heavily on this effort. Furthermore, in-situ material testing and intervention material design can be directed according to quantified requirements of structural design according to the envisaged use, performance level and load demand.

In summary, guidance to and coordination with other consulting disciplines should be sought on the basis of the proper use of knowledge based tools rather than with the purpose of satisfying the typical requirement of the consulting services of a structural engineer. The example of the Daphni Monastery, a UNESCO World Heritage site near Athens, is a well known multi-disciplinary restoration project, with substantial contributions my structural engineers (Miltiadou-Fezans 2008).

\section{CONCLUSIONS}

The expertise of structural engineers in conservation is both hard earned and underutilized. This fact is not helped by the state of interdisciplinary cooperation in architectural conservation projects, which often leaves a lot to be desired. It is not actively sought or encouraged, often leading to a parallel function of the involved consulting disciplines. Conditions are, however, sufficiently mature for the adoption of closer collaboration practices, following a close reexamination of the distinct roles and capacities of each discipline.

Structural engineers need to be allowed to assume a more decisive role in the conceptual, design, implementation and management phase of the project. This will allow them to bring to bear their expertise to maximum effect and to minimize the effects of foreseeable obstacles related to their field. sonry walls from point cloud data. In 11th International Conference on Structural Analysis of Historical Constructions.

CEN (2005). EN 1998-3 - Eurocode 8: Design of structures for earthquake resistance - Part 3: Assessment and retrofitting of buildings.

Heras Barros, V. (2014). Towards a 3D GIS based monitoring tool for Preventive Conservation Management of the World Heritage City of Cuenca. Ph. D. thesis, Catholic University of Leuven, Leuven.

Lagomarsino, S. (2015). Seismic assessment of rocking masonry structures. Bulletin of Earthquake Engineering 13(1), 97128.

Miltiadou-Fezans, A. (2008). A multidisciplinary approach for the structural restoration of the Katholikon of Dafni monastery in Attica Greece. In Structural Analysis of Historic Construction: Preserving Safety and Significance - Proceedings of the 6th International Conference on Structural Analysis of Historic Construction, SAHCO8, Volume 1, pp. 71-87.

Ministero per i Beni e le Attività Culturali (2008). Linee Guida per la valutazione e riduzione del rischio sismico del patrimonio culturale.

Psycharis, I. N., A. Drougkas, \& M. E. Dasiou (2010). Seismic Behaviour of the Walls of the Parthenon: A Numerical Study. In Computational Methods in Earthquake Engineering (Computational Methods in Applied Sciences, Vol. 21), pp. 265-283.

Spyrakos, C. (2015). Modern Approaches for the Earthquake Protection of Cultural Heritage Structures - Review and Proposal. In 4th Hellenic Conference on Restoration, Thessaloniki, Greece.

The Athens Charter (1931). The Athens Charter for the Restoration of Historic Monuments. In First International Congress of Architects and Technicians of Historic Monuments, Athens, Greece.

The Venice Charter (1964). The Venice Charter for the Conservation and Restoration of Monuments and Sites. In IInd International Congress of Architects and Technicians of Historic Monuments, Venice, Italy.

Toumbakari, E. E. (2008). Analysis and interpretation of the structural failures of the orthostate in the northern wall of the Athens parthenon. In 6th International Conference on Structural Analysis of Historical Constructions, Bath, United Kingdom, pp. 673-681.

United Nations Office for Disaster Risk Reduction (2015). Sendai Framework for Disaster Risk Reduction 2015 - 2030.

Verstrynge, E., L. Schueremans, S. Ignoul, \& D. Van Gemert (2010). Long-term Behaviour of Low Quality Sandstone Masonry: Assessment Methodology and Case Study. International Journal for Restoration of Buildings and Monuments 16(6), 435-448.

\section{REFERENCES}

Bassier, M., G. Hardy, L.-E. Bejarano-Urrego, A. Drougkas, E. Verstrynge, K. Van Balen, \& M. Vergauwen (2018). Semiautomated creation of accurate FEM meshes of heritage ma- 